\title{
Analisis Tingkat Maturitas Implementasi Manajemen Risiko di IPB University
}

\section{Analysis of The Maturity Level of Risk Management Implementation at IPB University}

\author{
Ryandi Simanjuntak \\ Sekolah Pasca Sarjana, Sekolah Bisnis, IPB University, Jl. Raya Padjajaran, Bogor 16128 \\ email: ryandisimanjuntak16@gmail.com \\ D S Priyarsono \\ Sekolah Pasca Sarjana, Sekolah Bisnis, IPB University, Jl. Raya Padjajaran, Bogor 16128 \\ email: priyarsono@yahoo.com \\ Titik Sumarti \\ Sekolah Pasca Sarjana, Sekolah Bisnis, IPB University, Jl. Raya Padjajaran, Bogor 16128 \\ email: titiksumarti61@gmail.com
}

\begin{abstract}
The implementation of risk management will not always achieve its goals. This problem can be caused by lack of consistency during the risk management implementation or it can not adapt to environmental changes. Therefore, an organization needs to measure the maturity level of the organization's risk management implementation. This research aims to analyze the maturity level of risk management implementation at IPB University. The research was conducted at IPB University, and it was using primary and secondary data. Research shows that the characteristics that need to be measured, or the attributes that need to be measured, in measuring the maturity level of risk management implementation at IPB University are risk culture, risk management framework, risk management process and risk management documents. The attributes will have their indicators, parameters, and test factors. The result of the measuring of maturity level of risk management implementation at IPB University indicates that risk management at IPB University has been implemented systematically and the implementation has referred to the standard consistently and comprehensively. Risk management has begun to be integrated to organization governance and management. The risk management competence, leadership, and commitment are starting to expand through the organization but the positive attitudes in managing risk is still tend to be limited.
\end{abstract}

Keywords: Risk management, ISO 31000, risk management maturity level.

\section{ABSTRAK}

Implementasi manajemen risiko di sebuah organisasi tidak selalu berhasil mencapai tujuaannya. Permasalahan ni dapat disebabkan oleh kurangnya konsistensi dalam implementasi atau organisasi tidak dapat beradaptasi dengan perubahan lingkungan yang terjadi. Oleh sebab itu, sebuah organisasi perlu untuk mengukur tingkat maturitas implementasi manajemen risiko di organisasi tersebut. Tujuan dari penelitian ini adalah untuk menganalisis tingkat maturitas implementasi manajemen risiko di IPB University. Penelitian ini dilaksanakan di IPB Univeristy dengan menggunakan data primer dan data sekunder. Hasil penelitian menyimpulkan bahwa karakteristik yang penting untuk diukur, atau sering disebut dengan atribut, dalam pengukuran tingkat maturitas implementasi manajemen risiko di IPB University adalah budaya risiko, kerangka kerja manajemen risiko, proses manajemen risiko dan dokumentasi manajemen risiko. Atribut tersebut akan dilengkapi dengan indikator, parameter dan faktor uji. Hasil pengolahan data yang diperoleh dari kuisioner yang disebarkan kepada responden, disimpulkan bahwa pengelolaan risiko di IPB University telah berlangsung secara sistematis dengan mengacu pada standar secara konsisten dan menyeluruh, dan mulai terintegrasi dengan tata kelola dan pengelolaan organisasi dengan kompetensi, kepemimpinan, dan komitmen manajemen risiko yang mulai meluas namun dengan perilaku positif dalam mengelola risiko yang cenderung masih terbatas.

Kata kunci: Manajemen risiko, ISO 31000, tingkat maturitas manajemen risiko. 


\section{PENDAHULUAN}

Implementasi manajemen risiko sudah umum diterapkan pada organisasi-organisasi. Target dari implementasi manajemen risiko menurut McKinsey (2014) adalah untuk:

1. Melindungi nilai dengan memastikan tingkat keberhasilan pencapaian tujuan, menghindari kerugian atau kesalahan dengan skala yang besar dan untuk menghindari volatilitas rugi laba.

2. Mendorong pertumbuhan profitabilitas.

3. Memastikan kepatuhan terhadap regulasi, dan menghindari klaim karena ketidakmampuan menjalankan aturan.

4. Memberikan kestabilan, kontinuitas dan kemandirian.

Menurut McKinsey (2018), implementasi manajemen risiko yang belum cukup baik terjadi pada perusahaan nonfinancial. Perhatian pemimpin-pemimpin perusahaan nonfinancial pada manajemen risiko masih minim dan bukan menjadi prioritas. Merujuk pada hasil temuan McKinsey tersebut, implementasi manajemen risiko pada Universitas sebagai sebuah organisasi nonfinansial masih minim dan bukan menjadi prioritas. Sementara menurut Toma et al. (2014) risiko tidak hanya dialami oleh korporasi besar, bank, organisasi nirlaba, pemerintahan tetapi juga organisasi pendidikan tinggi. Selanjutnya Toma et al. (2014) memperkuat penyataan dari McKinsey bahwa implementasi manajemen risiko di organisasi akademik masih lebih rendah jika dibandingkan dengan organisasi-organisasi lain pada umumnya.

IPB University merupakan salah satu perguruan tinggi yang telah menerapkan manajemen risiko sejak tahun 2018. IPB University merupakan salah satu perguruan tinggi pertama di Indonesia, selain Universitas Indonesia, yang menerapkan manajemen risiko. Menurut Priyarsono et al. (2019), terdapat dua poin penting yang menjadi komitmen awal IPB University dalam implementasi manajemen risiko, yaitu kesadaran yang memadai mengenai manajemen risiko diantara para stake holder. Poin kedua adalah standar yang akan digunakan dalam implementasi manajemen risiko adalah ISO 31000.

Rektor IPB University, dikutip dari sebuah media nasional, mengungkapkan bahwa pertimbangan bio-risiko akan menjadi panduan dalam implementasi pembukaan kembali kampus di era new normal (dapat dilihat pada: https://www.kompas.com/edu/read/2020/06/02/194048771 /jelang-kesiapan-new-normal-ini-pembelajaran-dari-ipb-university?page=all). Menurut Proença et al. (2017), implementasi manajemen risiko tidak selalu berhasil mencapai sasaran yang sudah ditetapkan. Hal tersebut dapat disebabkan karena organisasi tidak dapat menerapkan manajemen risiko secara konsisten atau tidak dapat beradaptasi dengan perubahan lingkungan yang terjadi. Menurut Yazici (2009), terdapat hubungan antara tingkat maturitas sebuah organisasi dengan kinerja dari organisasi tersebut di mana dengan tingkat maturitas yang tinggi organisasi dapat menjadi lebih efisien dan efektif. Agar pengolaan sumber daya dan implementasi aktivitas kampus di IPB University dapat mempertimbangkan risiko dan juga bio-risk, dibutuhkan sebuah implementasi risiko yang andal. Tingkat keandalan implementasi manajemen risiko di IPB University dapat diukur dari maturitas implementasi manajemen risiko.

Secara umum, tujuan dari penelitian ini adalah untuk mengukur tingkat maturitas implementasi manajemen risiko di IPB University. Secara lebih rinci, tujuan dari penelitian ini adalah:

1. Merumuskan alat ukur yang akan digunakan dalam menganalisis tingkat maturitas implementasi manajemen risiko di IPB University.

2. Melakukan pengukuran tingkat maturitas implementasi manajemen risiko di IPB University.

3. Merekomendasikan perbaikan-perbaikan yang perlu dilakukan oleh IPB University berdasarkan hasil pengukuran tingkat maturitas implementasi manajemen risiko di IPB University.

\section{METODE PENELITIAN}

Penelitian ini dilaksanakan tahun 2020. Tempat dilaksanakannnya penelitian ini adalah di IPB University yang berlokasi di Jl. Raya Dramaga, Kampus IPB Dramaga Bogor, 16680 Jawa Barat, Indonesia. Jenis data yang digunakan dalam penelitian ini adalah data primer dan data 
sekunder. Sifat data yang digunakan adalah kualitatif dan kuantitatif. Data Primer diperoleh melalui penyebaran kuisioner. Sementara data sekunder diperoleh dari hasil studi literatur Pemilihan responden untuk kuisioner dilakukan dengan menggunakan purposive sampling, di mana pemilihan responden dilakukan berdasarkan keahlian calon responden mengenai subyek yang diteliti. Profil responden dapat dilihat pada pada Tabel 1.

Tabel 1. Sampel responden penelitian

\begin{tabular}{lcc}
\hline \multicolumn{1}{c}{ Jabatan } & Gelar Akademik & Masa Kerja \\
\hline Waka KMRPLK & Doktor & 26 tahun \\
Pemilik risiko & Doktor & 15 tahun \\
Tim Manajemen Risiko IPB & Doktor & 31 tahun \\
Tim Manajemen Risiko IPB & Doktor & 15 tahun \\
Tim Ad hoc Manajemen Risiko IPB & Master & 5 tahun \\
\hline
\end{tabular}

Penelitian dilakukan dengan berlandaskan pada manajemen risiko ISO 31000. Adapun metode pegolahan dan analisis data berdasarkan tiap-tiap tujuan penelitian ini dapat dilihat pada Tabel 2.

Tabel 2. Tahapan pengolahan dan analisis data

\begin{tabular}{lll}
\hline \multicolumn{1}{c}{ Tujuan } & \multicolumn{1}{c}{ Alat Analisis } & \multicolumn{1}{c}{ Output } \\
\hline $\begin{array}{l}\text { Merumuskan alat } \\
\text { pengukuran. }\end{array}$ & Studi literatur & $\begin{array}{l}\text { Atribut, indikator, parameter dan faktor uji yang akan } \\
\text { digunakan dalam pengukuran tingkat maturitas } \\
\text { implementasi manajemen risiko di IPB University } \\
\text { Tingkat maturitas implementasi manajemen risiko di }\end{array}$ \\
$\begin{array}{l}\text { Pengukuran tingkat } \\
\text { maturitas. }\end{array}$ & Kuisioner & $\begin{array}{l}\text { IPB University. } \\
\text { Merumuskan }\end{array}$ \\
rekomendasi. & Studi literatur & $\begin{array}{l}\text { Rekomendasi perbaikan-perbaikan implementasi } \\
\text { manajemen risiko di IPB University. }\end{array}$ \\
\hline
\end{tabular}

\section{Merumuskan Alat Pengukuran}

Penetapan atribut yang akan diukur dalam pengukuran tingkat maturitas manajemen risiko di IPB University dilakukan dengan studi literatur. Atribut yang akan diukur adalah dengan berlandaskan pada prinsip, kerangka kerja, serta proses manajemen risiko ISO 31000. Selain itu, atribut yang akan diukur dalam pengukuran tingkat maturitas manajemen risiko di IPB University juga merujuk pada atribut-atribut yang sudah ditetapkan oleh AON (2019) dan juga RIMS Risk Maturity Model (2006).

Penetapan alat pengukuran yang terdiri dari indikator, parameter serta faktor uji tingkat maturitas manajemen risiko di IPB University ditentukan dengan mempertimbangkan beberapa hal. Pertimbangan pertama adalah dengan merujuk pada road map implementasi manajemen risiko di universitas menurut Gallagher (2009). Gallagher (2009), menyebutkan bahwa tahaptahap implementasi manajemen risiko terdiri dari empat tahap di mana dalam setiap tahap terdapat aktivitas-aktivitas inti yang penting untuk dilakukan sebuah organisasi. Road map implementasi manajemen risiko di universitas menurut Gallagher (2009) dapat dilihat pada Tabel 3. 
Tabel 3. Road map implementasi manajemen risiko di universitas

\begin{tabular}{|c|c|}
\hline Tahap & Langkah \\
\hline Memahami & Memahami rencana, lingkungan, dan budaya institusi. \\
\hline organisasi dan & Menentukan proses manajemen risiko yang ada saat ini. \\
\hline \multirow[t]{3}{*}{ konteksnya. } & Menyatakan tujuan dan sasaran organisasi saat ini. \\
\hline & Menyajikan kasus. \\
\hline & 5. Mendapatkan dukungan, komitmen dan partisipasi dari pimpinan puncak. \\
\hline \multirow{6}{*}{$\begin{array}{l}\text { Membangun pondasi } \\
\text { manajemen risiko. }\end{array}$} & Menunjuk pemimpin implementasi manajemen risiko. \\
\hline & Merencanakan proyek dan membuat timeline. \\
\hline & $\begin{array}{l}\text { 8. Memilih atau merancang sebuah kerangka kerja manajemen risiko yang } \\
\text { sesuai dengan tujuan dan budaya organisasi. }\end{array}$ \\
\hline & 9. Membentuk dewan risiko lintas fungsional. \\
\hline & Membuat pernyataan misi dan tujuan dari dewan risiko. \\
\hline & 11. Mengembangkan definisi yang sama mengenai manajemen risiko. \\
\hline \multirow[t]{3}{*}{ Implementasi } & 12. Mengembangkan portofolio risiko. \\
\hline & 13. Menilai risiko organisasi: validasi dan prioritas. \\
\hline & 14. Menetapkan kepemilikan risiko dan pengambilan tindakan. \\
\hline \multirow{6}{*}{$\begin{array}{l}\text { Keberlanjuntan } \\
\text { program manajemen } \\
\text { risiko. }\end{array}$} & Menilai hasil. \\
\hline & 16. Melakukan pertemuan dan pelaporan. \\
\hline & 17. Tinjau dan atur ulang perlakuan risiko dengan sumber daya yang tersedia. \\
\hline & 18. Jangan mengabaikan fungsi manajemen risiko tradisional. \\
\hline & 19. Meninjau kerangka kerja manajemen risiko yang telah dipilih untuk diikuti. \\
\hline & Mengembangkan sistem komunikasi yang terintegrasi. \\
\hline
\end{tabular}

Pertimbangan kedua adalah kunci keberhasilan implementasi manajemen risiko di universitas menurut Figueroa (2016), Tilly (2019), serta Vandeberg dan Wright (2017) yaitu:

1. Pemimpin dari sebuah universitas merupakan kunci keberhasilan implementasi manajemen risiko di universitas tersebut.

2. Pemimpin universitas perlu mengetahui dan memahami implementasi manajemen risiko di universitas yang mereka pimpin.

3. Dalam implementasi manajemen risiko yang matang, para pemilik risiko dapat dengan mudah untuk menindaklanjuti setiap risiko pada area mereka masing-masing dan berpotensi memberi dampak negatif bagi pencapaian tujuan universitas secara keseluruhan.

4. Pemimpin universitas menerima laporan dari pemilik risiko sebagai representasi dari risiko di areanya.

5. Pemimpin universitas melakukan monitor risiko yang dilaporkan oleh para pemilik risiko.

6. Manajemen risiko bukanlah sebuah proses yang kaku, oleh karena itu pemimpin universitas telah menganalisis nilai apa yang mereka inginkan dari implementasi manajemen risiko dan menentukan bagian mana yang paling cocok untuk diterapkan di universitas terutama pada saat awal implementasi.

7. Beberapa komponen manajemen risiko yang diterapkan secara mendalam oleh universitas adalah penentuan tujuan, identifikasi kejadian-kejadian, penilaian risiko, respon terhadap risiko, dan pemantauan risiko.

8. Sebuah struktur organisasi harus dibangun untuk mendukung proses manajemen risiko.

9. Individu di seluruh tingkatan di universitas harus dilibatkan dalam implementasi manajemen risiko.

\section{Pengukuran Tingkat Maturitas}

Menurut Alijoyo et al. (2020), pengukuran tingkat maturitas dilakukan dengan penyebaran kuisioner kepada responden. Kuisioner berisi pertanyaan-pertanyaan yang terdiri dari faktor uji dari masing-masing atribut, indikator, dan parameter yang sebelumnya telah disusun oleh penulis. Pemberian nilai pada masing-masing faktor uji dilakukan dengan pemberian skala ordinal dengan keterangan sebagai berikut:

1. 1 (satu), jika faktor uji belum diimplementasikan di IPB University, 
2. 2 (dua), jika faktor uji sudah diimplementasikan di IPB University dengan skala 0 persen < $\mathrm{x} \leq 25$ persen,

3. 3 (tiga), jika faktor uji sudah diimplementasikan di IPB University dengan skala 25 persen < $\mathrm{x} \leq 50$ persen,

4. 4 (empat), jika faktor uji sudah diimplementasikan di IPB University dengan skala 50 persen $<\mathrm{x} \leq 75$ persen,

5. 5 (lima), jika faktor uji sudah diimplementasikan di IPB University dengan skala 75 persen $<\mathrm{x} \leq 100$ persen.

Menurut RIMS Risk Maturity Model (2006), tingkat maturitas implementasi manajemen risiko terdiri dari initial, repeatable, defined, managed, dan optimizing. Initial adalah suatu kondisi di mana pengelolaan risiko masih bersifat ad hoc, mengandalkan inisiatif individual, dan bersifat silo/terbatas pada suatu aspek risiko/pengelolaan risiko tertentu saja/ mengandalkan tindakan perbaikan. Masing-masing atribut memiliki tingkat maturitas inital adalah jika nilai rata hasil kuisioner $\mathrm{x}=1$.

Repatable adalah kondisi di mana pengelolaan risiko mulai berlangsung secara sistematis, cenderung masih terpisah dari tata kelola dan pengelolaan organisasi dengan dukungan kompetensi, kepemimpinan, dan komitmen manajemen risiko yang tidak merata. Masing-masing atribut memiliki tingkat maturitas repeatable adalah jika nilai rata hasil kuisioner $1<\mathrm{x} \leq 2$.

Defined adalah kondisi di mana pengelolaan risiko telah berlangsung secara sistematis dengan mengacu pada standar secara konsisten dan menyeluruh, dan mulai terintegrasi dengan tata kelola dan pengelolaan organisasi dengan kompetensi, kepemimpinan, dan komitmen manajemen risiko yang mulai meluas namun dengan perilaku positif dalam mengelola risiko yang cenderung masih terbatas. Masing-masing atribut memiliki tingkat maturitas defined adalah jika nilai rata hasil kuisioner $2<\mathrm{x} \leq 3$.

Managed adalah kondisi di mana pengelolaan risiko telah terintegrasi dengan tata kelola dan di sebagian besar pengelolaan organisasi serta telah menjadi budaya, dengan dukungan kompetensi, kepemimpinan, dan komitmen manajemen risiko yang kuat, perilaku positif dalam mengelola risiko yang merata di sebagian besar lingkungan organisasi, serta didukung dengan tinjauan, perbaikan, dan peningkatan sesuai kebutuhan secara konsisten. Masing-masing atribut memiliki tingkat maturitas managed adalah jika nilai rata hasil kuisioner $3<\mathrm{x} \leq 4$.

Sementara optimizing adalah kondisi di mana Pengelolaan Risiko merupakan bagian tidak terpisahkan dari tata kelola dan pengelolaan organisasi karena telah menjadi budaya organisasi yang mengakar dan terinternalisasi, dengan kompetensi, kepemimpinan, dan komitmen implementasi manajemen risiko yang kokoh, serta perilaku positif dalam pengelolaan risiko yang sudah mewujud di berbagai tingkatan organisasi, didukung dengan tinjauan, perbaikan, dan peningkatannya sesuai kebutuhan termasuk kebutuhan spesifik yang diperlukan. Masing-masing atribut memiliki tingkat maturitas optimizing adalah jika nilai rata hasil kuisioner $4<\mathrm{x} \leq 5$.

\section{Merumuskan Tindak Lanjut}

Tindak lanjut dalam penelitian adalah tindakan untuk mengatasi permasalahanpermasalahan yang ditemukan dalam penelitian. Menurut Brown et al. (2006), tidak ada pedoman umum dalam memformulasikan tindak lanjut dari sebuah penelitian. Akan tetapi ada ada beberapa elemen yang penting untuk diperhatikan dalam memformulasikan tindak lanjut yaitu evidence, population, intervention, comparison, outcome dan time. Elemen-elemen tersebut harus disesuaikan dengan tipe penelitian yang sedang dilakukan.

Tindak lanjut dalam penelitian ini akan menggunakan hasil pengukuran tingkat maturitas manajemen risiko di IPB University sebagai evidence. Tindak lanjut yang diberikan akan secara langsung merespon hasil pengukuran tingkat maturitas manajemen risiko di IPB University. 


\section{HASIL DAN PEMBAHASAN}

\section{Alat Pengukuran Tingkat Maturitas Manajemen Risiko Di IPB University}

Karakteristik atau atribut yang diukur dalam pengukuran tingkat maturitas implemetasi manajemen risiko di IPB University adalah budaya risiko, kerangka kerja manajemen risiko, proses manajemen risiko, dan dokumen manajemen risiko.

Budaya Risiko

Budaya risiko dalam manajemen risiko ISO 31000 diartikan bahwa kondisi di mana semua individu di IPB University dan juga stakeholder menyadari pentingnya memonitor dan memanage risiko. Budaya risiko di IPB University juga dapat diartikan sebagai sebuah kondisi di mana nilai dan perilaku risiko hadir di dalam setiap keputusan IPB University. Indikator, parameter beserta faktor uji dari atribut budaya risiko dapat dilihat pada Tabel 4.

Tabel 4. Indikator, parameter dan faktor uji atribut budaya risiko

\begin{tabular}{|c|c|c|}
\hline Indikator & Parameter & Faktor Uji \\
\hline $\begin{array}{l}\text { Pendekatan risiko } \\
\text { yang dilakukan oleh } \\
\text { pemimpin }\end{array}$ & $\begin{array}{l}\text { Pemimpin mengetahui } \\
\text { dan memahami } \\
\text { implementasi } \\
\text { manajemen risiko di } \\
\text { Universitas yang } \\
\text { mereka pimpin. }\end{array}$ & $\begin{array}{l}\text { Pemimpin IPB University telah menyertakan } \\
\text { manajemen risiko dalam penetapan strategi, sasaran, } \\
\text { dan budaya IPB University. } \\
\text { Pemimpin IPB University telah menjadi panutan } \\
\text { dalam hal perilaku menghadapi risiko. } \\
\text { Pemimpin IPB University mendapat pengakuan dan } \\
\text { apresiasi dari individu-individu yang ada di IPB } \\
\text { University sebagai inspirator dan motivator dalam hal } \\
\text { manajemen risiko. } \\
\text { Pempinan IPB University telah mengkomunikasikan } \\
\text { tata nilai risiko di berbagai media yang tersedia di IPB } \\
\text { University, baik offline dan online. }\end{array}$ \\
\hline Akuntabilitas & $\begin{array}{l}\text { Peran, kewenangan, } \\
\text { tanggung jawab, dan } \\
\text { akuntabilitas terhadap } \\
\text { implementasi } \\
\text { manajemen risiko telah } \\
\text { ditetapkan. }\end{array}$ & $\begin{array}{l}\text { Surat Keputusan Pemimpin IPB University atau bukti } \\
\text { lain tentang pembagian akuntabilitas manajemen } \\
\text { risiko. } \\
\text { Semua pemegang akuntabilitas dalam tata kelola } \\
\text { risiko di IPB University dapat menjelaskan dengan } \\
\text { gamblang peran dan tanggung jawabnya. } \\
\text { Sudah ada kajian auditor internal atau pihak lain } \\
\text { berkompeten bahwa kedudukan fungsi manajemen } \\
\text { risiko dalam struktur organisasi saat ini telah sesuai } \\
\text { kebutuhan. }\end{array}$ \\
\hline \multirow[t]{2}{*}{$\begin{array}{l}\text { Penguatan budaya } \\
\text { risiko melalui tata } \\
\text { kelola organisasi }\end{array}$} & $\begin{array}{l}\text { Penetapan sasaran atau } \\
\text { indikator kinerja } \\
\text { manajemen risiko. } \\
\text { Manajemen } \\
\text { sumberdaya manusia } \\
\text { yang berlandaskan } \\
\text { pada manajemen risiko. }\end{array}$ & $\begin{array}{l}\text { Setiap unit kinerja di IPB University memiliki Key } \\
\text { Peformance Indicator (KPI) yang dilengkapi dengan } \\
\text { manajemen risiko. } \\
\text { Sudah ada pelatihan, perencanaaan dan manajemen } \\
\text { sumberdaya manusia yang berlandaskan pada } \\
\text { manajemen risiko. } \\
\text { Hasil evaluasi budaya risiko atau sumber data lainnya } \\
\text { menunjukkan bahwa keahlian manajemen risiko telah } \\
\text { tersebar merata di seluruh area IPB University sesuai } \\
\text { kebutuhan. }\end{array}$ \\
\hline & $\begin{array}{l}\text { Penetapan selera risiko } \\
\text { (risk appetite). }\end{array}$ & $\begin{array}{l}\text { Pemimpin IPB University telah mengkomunikasikan } \\
\text { manfaat risk appetite dan risk tolerance bagi } \\
\text { pengambilan keputusan yang efektif. } \\
\text { Surat keputusan dari pemimpin IPB University atau } \\
\text { bukti lain tentang pemberlakuan risk appetite. }\end{array}$ \\
\hline
\end{tabular}

Kerangka Manajemen Risiko

Kerangka kerja manajemen risiko merupakan landasan dan fondasi tata kelola manajemen risiko yang memiliki peran dan tujuan untuk membantu organisasi dalam mengintegrasikan manajemen risiko ke seluruh fungsi dan kegiatan organisasi. Indikator, parameter serta faktor uji dari atribut kerangka kerja manajemen risiko dapat dilihat pada Tabel 5. 
Tabel 5. Indikator, parameter dan faktor uji atribut kerangka kerja manajemen risiko

\begin{tabular}{|c|c|c|}
\hline Indikator & Parameter & Faktor Uji \\
\hline $\begin{array}{l}\text { Komitmen } \\
\text { pemimpin dalam } \\
\text { implementasi } \\
\text { Manajemen } \\
\text { Risiko }\end{array}$ & $\begin{array}{lr}\text { Peranan } & \text { pemimpin } \\
\text { dalam } & \text { implementasi } \\
\text { manajemen risiko. }\end{array}$ & $\begin{array}{l}\text { Manajemen risiko di IPB University sudah selaras dengan } \\
\text { strategi, dan sasaran organisasi. } \\
\text { Pemimpin IPB University sudah memiliki cara } \\
\text { pemantauan manajemen risiko yang sistematis dan } \\
\text { memadai sehingga risiko terkendali dan kerangka kerja } \\
\text { manajemen risiko tetap terjaga keefektifannya. } \\
\text { Pemimpin IPB University sudah mempunyai pemahaman } \\
\text { mengenai risiko utama yang dihadapi IPB University } \\
\text { dalam upaya mencapai sasarannya. }\end{array}$ \\
\hline Integrasi & $\begin{array}{l}\text { Pengintegrasian } \\
\text { manajemen risiko } \\
\text { bersifat dinamis dan } \\
\text { berulang serta sesuai } \\
\text { kebutuhan budaya } \\
\text { organisasi }\end{array}$ & $\begin{array}{l}\text { Pengintegrasian manajemen risiko di IPB University } \\
\text { sudah relevan dan selaras dengan kondisi budaya IPB } \\
\text { University. } \\
\text { Rencana pelaksanaan integrasi manajemen risiko di IPB } \\
\text { University telah mencakup penetapan mekanisme } \\
\text { pengambilan keputusan yaitu apa, oleh siapa, kapan, dan } \\
\text { bagaimana. }\end{array}$ \\
\hline
\end{tabular}

Rencana pelaksanaan integrasi manajemen risiko di IPB University telah mencakup program pengembangan prosedur formal pengambilan keputusan berbasis risiko di setiap jenjang unit organisasi.

Pelaksanaan integrasi manajemen risiko di IPB University dipimpin dan dikendalikan oleh salah satu pemimpin IPB University sebagai Risk Leaders.

Para risk owner di setiap jenjang organisasi di IPB University melaksanakan integrasi dengan menjalankan proses manajemen risiko pada setiap proses organisasional yang menjadi tanggung jawabnya.

Desain kerangka Manajemen risiko Pemetaan konteks internal dan eksternal di IPB University kerja manajemen konteks internal dan risiko eksternal organisasi Artikulasi komitmen manajemen risiko yang terukur dan terkendali.

Sudah ada kebijakan dan prosedur tata kelola risiko yang sistematis, terstruktur serta terdokumentasi secara formal yang selaras dengan konteks IPB University.

Seluruh jajaran IPB University dapat menjelaskan dengan gamblang komitmen implementasi manajemen risiko dan perwujudannya.

Komunikasi konsultasi

dan Tersedia sistem informasi dan komunikasi manajemen risiko yang mendukung kebutuhan komunikasi data risiko dari manapun dan secara real time.

Tersedia fasilitas pelaporan data risiko dari risk owner dan/atau fungsi manajemen risiko kepada Pemimpin.

Implementasi manajemen risiko

Evaluasi
Rencana pelaksanaan manajemen risiko yang sistematis, terarah, terstruktur dan terkendali. Memantau memperbaiki keefektifan rancangan dan pelaksanaan semua kegiatan dalam kerangka kerja manajemen risiko
Rencana pelaksanaan manajemen risiko di IPB University telah sesuai dengan desain yang dibuat.

dan Telah tersedia dokumentasi pelaksanaan evaluasi yang valid mencakup pemantauan terhadap pelaksanaan intengrasi dan kerangka kerja secara keselurunan Telah tersedia dokumentasi pelaporan hasil evaluasi mencakup rekomendasi penyesuaian/adaptasi dan peningkatan pelaksanaan integrasi maupun kerangka kerja manajemen risiko secara keseluruhan. 
Proses Manajemen Risiko

Proses manajemen risiko adalah serangkaian langkah sistematis untuk membantu para pemilik sasarana mengelola peluang dan ancaman bagi ketercapaian sasaran secara sistematis, terukur, dan terkendali. Indikator, parameter, serta faktor uji dari atribut proses manajemen risiko dapat dilihat pada Tabel 6.

Tabel 6. Indikator, parameter dan faktor uji atribut proses manajemen risiko

\begin{tabular}{ll}
\hline \multicolumn{1}{c}{ Indikator } & \multicolumn{2}{c}{ Parameter } \\
\hline $\begin{array}{l}\text { Proses manajemen } \\
\text { risiko sudah sesuai } \\
\text { dengan standar yang } \\
\text { telah disepakati }\end{array}$ & $\begin{array}{l}\text { Proses inti dijalankan } \\
\text { terkendali. }\end{array}$ \\
& \\
& Proses penunjang \\
& dijalankan dan \\
& mendukung seluruh \\
& tahapan proses inti.
\end{tabular}

Faktor Uji

Proses manajemen Proses inti dijalankan Pengembangan lingkup, proses, dan kriteria bagi risiko sudah sesuai secara terukur dan pelaksanaan proses manajemen risiko di IPB dengan standar yang terkendali. University sudah terlaksana

Pelaksanaan asesmen risiko dan perlakuan risiko di IPB University sudah sesuai lingkup, konteks, dan kriteria. pelaksanaan tahapar
sudah terlakasana.

Mekanisme pemantauan dan peninjauan terhadap pelaksanaan tahapan proses inti di IPB University sudah terlaksana.

Mekanisme pencatatan dan pelaporan terhadap pelaksanaan tahapan proses inti di IPB University sudah terlaksana.

Proses manajemen risiko diintegrasikan ke dalam seluruh proses organisasional.
Setiap Unit memiliki rencana pengintegrasian proses manajemen risiko.
Sudah tersedia peta proses bisnis untuk dilakukan pengintegrasian manajemen risiko.

Penetapan sasaran dan target pengintegrasian manajemen risiko ke dalam seluruh proses bisnis di IPB University telah terpetakan.

Hasil pemetaan konteks internal dan eksternal ditetapkan sebagai sumber informasi untuk identifikasi risiko IPB University.

Kriteria untuk analisis dan evaluasi risiko di IPB University telah ditetapkan.

Setiap Unit Pelaksanaan asesmen risiko di IPB University sudah melaksanakan sesuai lingkup, konteks, dan kriteria yang pengintegrasian proses dikembangkan dalam rencana pengintegrasian proses manajemen risiko manajemen risiko di IPB University.

secara terukur dan Pemberian perlakuan risiko yang terencana dan efektif terkendali. sesuai hasil asesmen risiko yang telah dilaksanakan. Pemantauan dan peninjauan dilakukan terhadap keefektifan dan efisiensi pemberian perlakuan risiko maupun pengintegrasian proses manajemen risiko di IPB University secara keseluruhan sudah terlaksana. Pencatatan dan pelaporan telah dilakukan terhadap kinerja perlakuan risiko maupun kinerja pengintegrasian proses manajemen risiko di IPB University.

Komunikasi dan konsultasi sudah dilaksanakan secara terencana di setiap tahapan pelaksanaan integrasi proses manajemen risiko di IPB University.

Dokumen Manajemen Risiko

Dokumentasi yang baik adalah sebuah prasyarat keberhasilan implementasi manajemen risiko. Keberadaan dokumentasi manajemen risiko akan sangat membantu pengambilan keputusan. Dokumentasi manajemen risiko harus menyampaikan pesan yang konsisten, mudah dipahami, dan dapat ditinjau dan dievaluasi. Indikator, parameter, serta faktor uji dari atribut dokumen manajemen risiko dapat dilihat pada Tabel 7. 
Tabel 7. Indikator, parameter dan faktor uji atribut dokumentasi manajemen risiko

\begin{tabular}{|c|c|c|}
\hline Indikator & Parameter & Faktor Uji \\
\hline $\begin{array}{l}\text { Dokumentasi } \\
\text { Manajemen } \\
\text { Risiko }\end{array}$ & $\begin{array}{l}\text { Dokumentasi Kerangka } \\
\text { kerja dan proses } \\
\text { manajemen risiko. }\end{array}$ & $\begin{array}{l}\text { Telah tersedia dokumentasi proses penetapan risk } \\
\text { appetite dan risk tolerance oleh pemimpin. } \\
\text { Telah tersedia dokumentasi penggunaan risk appetite } \\
\text { dan risk tolerance dalam setiap pengambilan keputusan. } \\
\text { Telah tersedia dokumentasi kebijakan dan prosedur } \\
\text { manajemen risiko. } \\
\text { Dokumentasi daftar risiko telah tersedia di IPB } \\
\text { University. } \\
\text { Dokumentasi metode perlakuan terhadap risiko telah } \\
\text { tersedia di IPB University. } \\
\text { Dokumentasi komunikasi manajemen risiko telah } \\
\text { tersedia di IPB University. } \\
\text { Dokumentasi pelatihan manajemen risiko telah tersedia } \\
\text { di IPB University. }\end{array}$ \\
\hline
\end{tabular}

\section{Tingkat Maturitas Manajemen Risiko di IPB University}

\section{Budaya Risiko}

Berdasarkan hasil pengolahan data yang diperoleh melalui kuisioner, nilai rata-rata faktor uji budaya risiko di IPB University adalah 2,63. Hasil tersebut menunjukkan bahwa tingkat maturitas budaya risiko di IPB University berada pada tingkat defined. Bedasarkan hasil tersebut, dapat disimpulkan bahwa pengelolaan risiko di IPB University sudah berlangsung secara sistematis berdasarkan pada sistem tata kelola dengan didukung oleh kompetensi untuk mengelola risiko yang cenderung belum merata di berbagai tingkatan.

Kerangka Kerja Manajemen Risiko

Berdasarkan hasil pengolahan data yang diperoleh melalui kuisioner, nilai rata-rata faktor uji kerangka kerja manajemen risiko di IPB University adalah 2,65. Hasil tersebut menunjukkan bahwa tingkat maturitas kerangka kerja manajemen risiko di IPB University berada pada tingkat defined. Berdasarkan hasil tersebut, dapat disimpulkan bahwa di IPB University sudah ada kerangka kerja manajemen risiko yang mengacu pada standar dan mulai terintegrasi dengan misi, tata kelola, strategi, sasaran, dan operasional melalui proses desain, implementasi, evaluasi, dan peningkatan terhadap efektivitas manajemen risiko, dengan mulai mempertimbangkan kebutuhan organisasi, serta didukung oleh kepemimpinan dan komitmen yang kuat manajemen puncak.

Proses Manajemen Risiko

Berdasarkan hasil pengolahan data yang diperoleh melalui kuisioner, nilai rata-rata faktor uji proses manajemen risiko di IPB University adalah 2,28. Hasil tersebut menunjukkan bahwa tingkat maturitas proses manajemen risiko di IPB University berada pada tingkat defined. Berdasarkan hasil tersebut, dapat disimpulkan bahwa di IPB University sudah ada proses manajemen risiko yang mengacu pada standar, dan mulai dilaksanakan menurut suatu perencanaan sesuai kebutuhan organisasi untuk mengintegrasikan proses manajemen risiko ke dalam proses bisnis.

Dokumen Manajemen Risiko

Berdasarkan hasil pengolahan data yang diperoleh melalui kuisioner, nilai rata-rata faktor uji dokumen manajemen risiko di IPB University adalah 2,09. Hasil tersebut menunjukkan bahwa tingkat maturitas dokumen manajemen risiko di IPB University berada pada tingkat defined. Berdasarkan hasil tersebut, dapat disimpulkan bahwa di IPB University sudah ada dokumentasi manajemen risiko yang sudah sesuai dengan standar namun belum dapat diakses dengan mudah.

\section{Rekomendasi}

Hasil penelitian menunjukkan bahwa secara keseluruhan pengelolaan risiko di IPB

University berada pada tingkat maturitas defined. Hasil tersebut dapat diartikan bahwa implementasi manajemen risiko di IPB University telah berlangsung secara sistematis dan telah mengacu pada standar secara konsisten dan menyeluruh. Pengelolaan risiko mulai terintegrasi dengan tata kelola dan pengelolaan organisasi dengan kompetensi, kepemimpinan, dan komitmen 
manajemen risiko yang mulai meluas namun dengan perilaku positif dalam mengelola risiko yang cenderung masih terbatas. Hasil tersebut menunjukkan bahwa ada ada beberapa hal yang dapat diperbaiki dalam rangka memperbaiki penerapan manajemen risiko di IPB University. Beberapa rekomendasi dari penulis dapat dilihat pada Tabel 8.

Tabel 8. Rekomendasi

\begin{tabular}{cc}
\hline Evidence & Rekomendasi \\
\hline Kompetensi untuk mengelola risiko Pimpinan puncak IPB University melakukan pembagian
\end{tabular}
yang cenderung belum merata di akuntabilitas manajemen risiko.

berbagai tingkatan.

Kerangka kerja manajemen risiko yang mengacu pada standar dan mulai terintegrasi dengan misi, tata kelola, strategi, sasaran, dan operasional melalui proses desain, implementasi, evaluasi, dan peningkatan terhadap efektivitas manajemen risiko, dengan mulai mempertimbangkan kebutuhan organisasi, serta didukung oleh kepemimpinan dan komitmen yang kuat manajemen puncak belum menyebar ke jajaran manajemen lainnya.

Proses kerja manajemen risiko belum dilaksanakan menurut suatu perencanaan berkala dan/atau sesuai kebutuhan dalam mengintegrasikan manajemen risiko ke dalam proses bisnis.
Mengadakan kajiaan auditor internal untuk memastikan bahwa kedudukan fungsi manajemen risiko di IPB University telah sesuai dengan kebutuhan.

Pimpinan puncak IPB University mengkomunikaiskan manfaat risk appetite dan risk tolerance bagi pengambilan keputusan yang efektif.

Pemimpin IPB University menerbitkan dokumen formal tentang pemberlakuan risk appetite.

Tim manajemen risiko IPB University membuat metode pemantauan manajemen risiko yang sistematis dan memadai untuk digunakan oleh Pimpinan puncak IPB University.

Para risk owner di setiap jenjang organisasi di IPB University melaksanakan integrasi dengan menjalankan proses manajemen risiko pada setiap proses organisasional yang menjadi tanggung jawabnya.

Tim manajemen risiko IPB University membuat kebijakan dan prosedur tata kelola risiko yang sistematis, terstruktur serta terdokumentasi secara formal yang selaras dengan konteks IPB University.

Tim manajemen risiko IPB University menyediakan dokumentasi pelaksanaan evaluasi yang valid mencakup pemantauan terhadap pelaksanaan intengrasi dan kerangka kerja secara keselurunan.

Tim manajemen risiko IPB University menyediakan dokumentasi pelaporan hasil evaluasi mencakup rekomendasi penyesuaian/adaptasi dan peningkatan pelaksanaan integrasi maupun kerangka kerja manajemen risiko secara keseluruhan.

Tim manajemen risiko IPB Univesity menyesuaikan pelaksanaan asesmen risiko dan perlakuan risiko di IPB University dengan lingkup, konteks, dan kriteria.

Tim manajemen risiko IPB University memetakan penetapan sasaran dan target pengintegrasian manajemen risiko ke dalam seluruh proses bisnis di IPB University.

Tim manajemen risiko IPB University menetapkan kriteria untuk analisis dan evaluasi risiko.

Para risk owner memberikan perlakuan risiko yang terencana dan efektif sesuai hasil asesmen risiko.

Risk leader melakukan pemantauan dan peninjauan terhadap keefektifan dan efisiensi pemberian perlakuan risiko maupun pengintegrasian proses manajemen risiko di IPB University secara keseluruhan.

Tim manajemen risiko IPB University melakukan pencatatan dan pelaporan terhadap kinerja perlakuan risiko maupun kinerja pengintegrasian proses manajemen risiko.

Tim manajemen risiko IPB University melaksanakan komunikasi dan konsultasi secara terencana di setiap tahapan pelaksanaan integrasi proses manajemen risiko di IPB University. 


\begin{tabular}{lllll}
\hline \multicolumn{2}{c}{ Evidence } & \multicolumn{3}{c}{ Rekomendasi } \\
\hline Dokumen manajemen risiko belum & Tim manajemen risiko IPB University menyediakan \\
mudah untuk diakses. & dokumentasi proses penetapan risk appetite dan risk tolerance \\
& oleh pimpinan puncak. & \\
& Tim manajemn risiko IPB University menyediakan \\
& dokumentasi penggunaan risk appetite dan risk tolerance dalam \\
& setiap pengambilan keputusan. & \\
& Tim manajemen risiko IPB University menyediakan \\
& dokumentasi daftar risiko. & \\
& Tim manajemen risiko IPB University menyediakan \\
& dokumentasi metode perlakuan terhadap risiko. \\
& Tim manajemen risiko IPB University menyediakan \\
& dokumentasi komunikasi manajemen risiko. & \\
\hline
\end{tabular}

\section{KESIMPULAN}

Hasil pengolahan data yang diperoleh dari kuisioner yang disebarkan kepada responden, disimpulkan bahwa pengelolaan risiko di IPB University telah berlangsung secara sistematis dengan mengacu pada standar secara konsisten dan menyeluruh, dan mulai terintegrasi dengan tata kelola dan pengelolaan organisasi dengan kompetensi, kepemimpinan, dan komitmen manajemen risiko yang mulai meluas namun dengan perilaku positif dalam mengelola risiko yang cenderung masih terbatas. Tingkat maturitas implementasi manajemen risiko di IPB University saat ini memberikan ruang untuk perbaikan agar kinerja manajemen risiko di IPB University semakin membaik.

\section{DAFTAR PUSTAKA}

Alijoyo, F. A., Bonita, I., \& Sirait, K. B. (2020). The risk management maturity assessment: the case of Indonesian fintech firm. Asia-Pacific Management Review. [akan terbit].

AON. (2019). Risk Maturity Index 2.0. [internet]. [diakses pada: 2020 Juli 4]. Tersedia pada: https://www.aon.com/risk-maturity-index.

Brown, P., Brunnhuber, K., \& Chalkidou, K. (2006). How to formulate research recommendations. British Medical Journal. 333(7572): 804-806.

Figueroa, F. A., Hann, B., Lavagnino, M. B., \& Smith, M. (2016). Enterprise Risk Management for Academia. [internet]. [diakses pada: 2020 Juli 4]. Tersedia pada: https://acua.org/College-and-University-Auditor-Journal/Summer-2017/Enterprise-RiskManagement-Frameworks-for-Academia.

Gallagher. (2009). Road to Implementation Enterprise Risk Management for Colleges and Universities. [internet]. [diakses pada: 2020 Juli 4]. Tersedia pada: https://www.odu.edu/content/dam/odu/offices/risk-management/DOCS/erm-road-toimplementation-universities.pdf.

McKinsey. (2014). Enterprise-Risk-Management Practices: Where's the Evidence?. [internet]. [diakses pada: 2020 Juli 4]. Tersedia pada: https://www.mckinsey.com/businessfunctions/risk/our-insights/enterprise-risk-management-practices-where-is-the-evidence\#.

McKinsey. (2018). Value and Resilience Through Better Risk Management. [internet]. [diakses pada: 2020 Juli 4]. Tersedia pada: https://www.mckinsey.com/business-functions/risk/ourinsights/value-and-resilience-through-better-risk-management.

RIMS. (2006). RIMS Risk Maturity Model (RMM) for Enterprise Risk Management. [internet]. [diakses pada: 2020 juli 4]. Tersedia pada: https://www.logicmanager.com/pdf/rims_rmm_executive_summary.pdf. ça, D., Vieira, R., \& Borbinha, J. (2017). Risk management: a maturity model based on ISO 31000. IEEE 19th Conference on Business Informatics (CBI). Lisbon (PT): University of Lisbon. 
Priyarsono, D. S., Widhiani, A. P., \& Sari, D. L. (2019). Starting the implementation of risk management in a higher education institution: the case of IPB University. IOP Conf. Series: Materials Science and Engineering. 598. Bogor: IPB University.

Tilly, B. (2019). Lesson from Leading ERM Programs in Higher Education. [internet]. [diakses pada: 2020 Juli 4]. Tersedia pada: https://www.bakertilly.com/insights/lessons-fromleading-erm-programs-in-higher-education.

Toma, S. V., Alexa, I. V., \& Sarpe, D. A. (2014). Identifying the risk in higher education institutions. Procedia Economics and Finance, 15(14): 342-349.

Vandenberg, V., \& Wright, J. (2017). Enterprise Risk Management: Lessons for Higher Education. [internet]. [diakses pada: 2020 Juli 4]. Tersedia pada: https://www.plantemoran.com/explore-our-thinking/insight/2017/03/enterprise-riskmanagement-lessons-for-higher-education.

Yazici, H. J. (2009). The role of project management maturity and organizational culture in perceived performance. Project Management Journal, 40(3):14 - 33. 